\title{
Prevention of Stroke in Nonvalvular Atrial Fibrillation
}

\author{
M Ullah ${ }^{1}$, N Kar ${ }^{1}$, PK Karmakar ${ }^{1}$, S Alam ${ }^{1}$, MS Mamun ${ }^{1}$, T Rahman ${ }^{1}$, SMA Habib ${ }^{2}$, AAS Majumder ${ }^{1}$ \\ ${ }^{1}$ Department of Cardiology, National Institute of Cardiovascular Diseases, Dhaka, ${ }^{2}$ Department of \\ Cardiology, Bangabandhu Sheikh Mujib Medical University, Dhaka.
}

Key words:
Atrial
fibrillation,
Stroke,
Left atrial
appendage
occlusion device

\begin{abstract}
Cerebro-vascular Disease (CVD) is the third most common cause of death in developed world after cancer and IHD. Atrial fibrillation (AF) is responsible in $45 \%$ of cases cardioembolism leading to CVD. Atrial fibrillation is considered to be one of the growing cardiovascular epidemics in the $21^{\text {st }}$ century. Warfarin is a proven drug for prevention of stroke in patients with atrial fibrillation. Newer anticoagulants are being tried, fibrillation. Newer anticoagulants are being tried, but not yet well established by clinical trials. Separation of left atrial appendage from circulation by surgery or device implantation is a promising one in this field.
\end{abstract}

(CVJ 2008; 1(1) : 64-71)
Cerebro Vascular Disease (CVD) is third most common cause of death in developed world after cancer and IHD. $20 \%$ of cerebral infarctions are consequent upon embolism from heart. ${ }^{1}$ Among the different causes of cardioembolism, atrial fibrillation $(\mathrm{AF})$ is an important one and is responsible in $45 \%$ of cases. ${ }^{2}$ Non valvular atrial fibrillation is responsible for $15 \%$ of strokes. ${ }^{3}$ Moreover presence of $\mathrm{AF}$ in stroke patients increases the mortality by two folds. As reported by the Framingham Heart study, the annual incidence of stroke patients with nonvalvular heart disease is $4 \%$ to $5 \%$ per year. ${ }^{4}$

\section{What is Atrial Fibrillation?}

This is the rhythm disorder of heart where atria are activated by multiple wandering wavelets, and proportions of atrial impulses are conducted to ventricle. There is no coordinated contraction of atria leading to stasis of blood and thrombus formation in atria especially in its appendages.

\section{How important is this atrial fibrillation?}

Atrial fibrillation was first described in $1909 .{ }^{5}$ The common causes of atrial fibrillation are mitral valvular disease, IHD, thyrotoxicosis and hypertension. In developing world where rheumatic heart disease is still a problem mitral valvular disease is the commonest cause. On the other hand in developed world, nonvalvular AF is more common. In USA about 2.3 million people are suffering from Atrial fibrillation; ${ }^{6}$ this number is expected to rise to 3.3 million by 2020 and to 5.6 million by $2050 .{ }^{7}$ Indeed, atrial fibrillation is considered to be one of the three growing cardiovascular epidemics in the $21^{\text {st }}$ century in conjunction with congestive heart failure and type II diabetes mellitus and/or metabolic syndrome. ${ }^{8}$

Many episodes of atrial fibrillation remain undetected because of lack of symptoms. In one perspective study in USA between 1980 to 2000; among 4618 individuals with atrial fibrillation; $18 \%$ of patients had typical symptoms, rest were either asymptomatic or had atypical symptoms. ${ }^{9}$

\section{Causes of nonvalvular Atrial fibrillation-}

There are many causes that may be responsible for the occurrence of atrial fibrillation. In the Framingham Heart Study of 5000 men and women followed biennially for 24 years or till death, after rheumatic heart disease, cardiac failure, hypertensive heart disease and coronary heart disease are the most powerful predictors of atrial fibrillation. ${ }^{4}$ Besides these cardiomyopathy, cardiac surgery, thyrotoxicosis are also among the common causes.

\section{Investigations-}

These are mainly for diagnosis of atrial fibrillation, detection of underlying causes and complications that may develop. Routine investigations are-

i) ECG

ii) Echo- transthoracic and transesophageal.

iii) Chest X-ray.

iv) Thyroid function test

v) Other investigations- if the history, clinical features and above investigations suggest.

Risk factors of stroke in atrial fibrillation The risk of stroke in atrial fibrillation varies greatly depending on age and coexisting disease.

Address Correspondence : Dr Mohammad Ullah, Assistant Professor, Department of Cardiology, National Institute of Cardiovascular diseases, Dhaka. Email-dr_firoze_fcps@yahoo.com. 
Table-I Annual rate of stroke in nonvalvular atrial fibrillation per 100 patients $^{14}$

\begin{tabular}{|c|c|c|c|}
\hline & AFI & SPAF & CHADS2 \\
\hline $\begin{array}{l}\text { Risk factor } \\
\text { classification }\end{array}$ & $\begin{array}{l}\text { Low risk- } \\
\text { No risk factor } \\
\text { Moderate risk- Age> } 65 \text { yrs } \\
\text { High risk- DM, HTN, } \\
\text { Prior ischaemic events }\end{array}$ & $\begin{array}{l}\text { Low risk- } \\
\text { No risk factor } \\
\text { Moderate risk- HTN } \\
\text { High risk- Prior } \\
\text { ischaemic event, } \\
\text { women }>75 \text { yrs, } \\
\text { recent } \mathrm{CHF} \text { or } \mathrm{EF}<25 \% \text {, } \\
\mathrm{SBP}>160 \mathrm{~mm} \mathrm{Hg}\end{array}$ & $\begin{array}{l}1 \text { point for each of the } \\
\text { following: Recent CHF, HTN, } \\
\text { age > } 75 \text { yrs, DM. } 2 \text { points for prior } \\
\text { cerebral ischaemic event }\end{array}$ \\
\hline Low & & $1.5(0.5-2.8)$ & $\begin{array}{l}0: 1.9(1.2-3 . .0) \\
1: 2.8(2.0-3 . .3)\end{array}$ \\
\hline Moderate & $2.2(1.1-3.5)$ & $3.3(1.7-5.2)$ & $\begin{array}{l}2: 4.0(3.4-5 . .9) \\
3: 5.9(4.6-7.8)\end{array}$ \\
\hline High & $5.4(4.2-6.5)$ & $5.7(4.4-7.0)$ & $\begin{array}{l}4: 8.5(6.3-10.4) \\
5: 12.5(8.2-17.5) \\
6: 18.2(16.522 .4)\end{array}$ \\
\hline
\end{tabular}

AFI- Atrial Fibrillation Investigators; SPAF- Stroke Prevention in Atrial Fibrillation trial; CHADS2- Congestive Heart Failure, HTN, Age, DM \& Stroke.

Nonvalvular atrial fibrillation increases the risk of stroke by five folds and valvular atrial fibrillation by 17 folds, in both men and women. ${ }^{10}$ The proportion of stroke increases steadily with age, rising from $6.5 \%$ for ages 50 to 59 years to approximately $31 \%$ for ages 80 to 89 years. ${ }^{11}$ The risk of stroke in patients with nonvalvular atrial fibrillation increases also with the presence of hypertension, diabetes mellitus, female gender older than 75 years, previous TIA or stroke, CHF, or presence of LV dysfunction. ${ }^{12}$ In some studies left atrial enlargement, mitral annular calcification and increased left ventricular mass have been associated with a higher risk of stroke in some studies. ${ }^{13}$ Different study group used different risk stratification schemes mainly in nonvalvular atrial fibrillation. Table-I reveals three of them-

Prevention of stroke in Atrial fibrillation:

For prevention of stroke, three aspects of treatment should be considered in patients with atrial fibrillation-

a) Treatment of underlying disease, which will bring the patient in sinus rhythm permanently.

b) Conversion of atrial fibrillation to sinus rhythm and maintenance in sinus rhythm. But in patients with paroxysmal and chronic atrial fibrillation, even with maintenance of sinus rhythm, anticoagulant should be prescribed to prevent thromboembolism if risk factors of stroke are evident. ${ }^{15}$ Indeed rate of recurrence of stroke and/ or death in the first year remains high in these patients at $60 \%$.

c) Treatment of underlying disease, reduction of ventricular rate and use of anticoagulant to prevent thromboembolism or isolation of site of thrombus formation from the systemic circulation.

\section{Rate or rhythm control?}

One obvious question is whether conversion to sinus rhythm lowers the risk of thromboembolism in patients with atrial fibrillation. This question has been recently addressed in four studies, examining which method provides more effective protection against thromboembolism events, reduces mortality and offers better relief of symptoms or improved quality of life in patients of at least 65 years of age with a minimum of one additional risk factor of stroke. ${ }^{16}$ The Atrial Fibrillation Follow up Investigation of Rhythm Management (AFFIRM) trial ${ }^{17}$ randomized 4060 such patients to rate or rhythm control. Anticoagulation was maintained indefinitely in the rate control group and was 
encouraged in the rhythm control group. The primary outcome measure, overall mortality at 5 years was $23.8 \%$ and $21.3 \%$ in the rhythm control and rate control groups, respectively [hazard ratio, 1.15; 95\% confidence interval]. The incidences of stroke were $8.9 \%$ in the rhythm control group and $7.4 \%$ in the rate control group. In both groups, > $70 \%$ of strokes occurred in patients who stopped anticoagulant therapy, or in those where the international normalized ratio (INR) was $<2.0$. This trial, therefore, suggests that there is no increased benefit in terms of mortality or morbidity with aggressive rhythm control relative to rate control; findings that have been confirmed in the three smaller randomized clinical trials. ${ }^{18}$ In summary, therefore, treatment strategies that combine rate control with anticoagulation is as effective as rhythm control in most patients with atrial fibrillation.

\section{Anticoagulation in atrial fibrillation}

There are different trials for primary \& secondary prevention of stroke in atrial fibrillation with warfarin, warfarin with aspirin and aspirin alone. A pooled analysis of primary prevention trials using warfarin, demonstrated a $59 \%$ reduction in the relative risk of stroke. The relative risk reduction was $68 \%$ in the secondary prevention trial. The number needed to prevent one stroke over 1 year was 37 in primary prevention and 12 in secondary prevention. Indeed, all cause of mortality is reduced by $26 \%$ in patients receiving warfarin. ${ }^{19,20}$

Meta analysis of several trials (AFASAK-I, AFASAKII, PATAF SIFA, SPAF-II) revealed a greater risk reduction in stroke with warfarin than aspirin (RRR$32 \%)^{12}$. In EAFT study, it was revealed that, not only warfarin was more effective than aspirin, but also aspirin failed to reduce stroke. ${ }^{21}$

In SPAF (Stroke Prevention in Atrial Fibrillation) investigation compared low intensity fixed dose warfarin (INR 1.2 to 1.5 ) plus aspirin ( $325 \mathrm{mg} /$ day) with adjusted dose warfarin (INR 2.0 to 3.0). Ischaemic stroke and systemic embolism were present in $7.9 \%$ of patient as fixed dose warfarin plus aspirin vs. only $1.9 \%$ on adjusted dose warfarin. $^{22}$

However, because of complexities of administering warfarin including variable dose, monitoring of INR, contraindications and risk of bleeding specially in elderly person; alternative strategies have always been sought. Especially risk of bleeding and risk of thromboembolism should be balanced. There are different organizations with different guidelines for anticoagulation. The guideline in ACC/AHA/ESC consensus is as follows-

Table-II

Guideline for anticoagulation therapy

\begin{tabular}{ll}
\hline Patient features & Anticoagulation therapy \\
\hline Age $<60$ years, no heart disease (lone AF) & Aspirin (325 mg/day) or no therapy \\
Age $<60$ years, heart disease but no risk factor & Aspirin (325 mg/day) \\
$\begin{array}{l}\text { Age }>60 \text { years, no risk factors } \\
\text { Age }>60 \text { years with DM or CAD }\end{array}$ & $\begin{array}{l}\text { Oral anticoagulation (INR 2.0- 3.0), with or without } \\
\text { aspirin 81-162 mg/day }\end{array}$ \\
$\begin{array}{l}\text { Age }>75 \text { years, especially women } \\
\text { Heart failure }\end{array}$ & Oral anticoagulation (INR 2.0- 3.0) \\
$\begin{array}{l}\text { LV ejection fraction }<0.35, \text { thyrotoxicosis } \\
\text { and HTN }\end{array}$ & \\
$\begin{array}{l}\text { Rheumatic mitral stenosis } \\
\text { Prosthetic heart valves }\end{array}$ & Oral anticoagulation (INR 2.5- 3.5 or higher \\
$\begin{array}{l}\text { Prior thromboembolism } \\
\text { Persistent atrial thrombus on TEE }\end{array}$ & may be appropriate) \\
\hline
\end{tabular}




\section{Monitoring treatment:}

Monitoring of anticoagulant therapy, like all other cases, is with regular estimation of prothrombin time \& INR. INR $<2.0$ is associated with recurrent ischaemic event; on the other hand, INR > 4.0 may give rise to intracranial hemorrhage. Prothrombin time \& INR should be measured at an interval of 34 weeks $\&$ if there is any colonic condition or drug which may affect the coagulation system.

Meta analysis of 12 randomized clinical trials investigating the efficacy and tolerability of Vitamin $\mathrm{K}$ antagonists in the prevention of stroke in patients with atrial fibrillation have demonstrated an increased risk of major hemorrhages. This risk corresponds to a relative risk of 2.4 or an estimated annual absolute increase in risk of $0.3 \%{ }^{23,24}$

Newer anticoagulants

Warfarin has got number of limitations like-

a) Slow onset of action- warfarin needs 3-5 days to achieve the target INR.

b) Narrow therapeutic windows.

c) Interaction with number of drugs.

So, alternative pharmacological and nonpharmacological approaches are being looked for. Newer anticoagulant drugs are-

1) Ximelagatran: This is a direct thrombin inhibitor. It is used orally. It has got no drug or food interaction and it doesn't need any monitoring, so can be used in fixed dose. In SPORTIF V trial fixed dose Ximelagatran (36 mg b.d) was compared with warfarin. There was no significant difference between the primary event rates (thromboembolism); major bleeding was same. But the total bleeding rate was low in Ximelagatran group. There was significant increase in SGPT \& SGOT in first six months of treatment in ximelagatran group, but it returned to normal after six months whether ximelagtran was continued or not. The trial recommended further study to evaluate heapatotoxicity. ${ }^{25}$

2) Indraparinux: This is a synthetic analogue of heparin. It is used subcutaneously, once weekly. It has no drug or food interaction. It doesn't need any monitoring. The AMADEUS trial is the first to investigate the efficacy and safety of Indraparinux for prevention of stroke in patients with AF. The trial was prematurely stopped because of greater bleeding with Indraparinux than with vitamin $\mathrm{K}$ antagonist (19.7 vs. 11.3 per 100 patient years). However mortality didn't differ between the groups. The AMADEUS investigators concluded that a regimen of Indraparinux with dose adjusted for age and creatinine clearance might preserve efficacy without an increased risk of hemorrhage. ${ }^{26}$

\section{Cardioversion in atrial fibrillation-}

Conversion of atrial fibrillation to sinus rhythm can be done in several ways-

i) Pharmacological - by using drugs like Amiodarone, Sotalol, Dofetelide, Ibutulide.

ii) Surgery and ablation therapy.

AFFIRM trial demonstrated that the use of a rhythm control strategy does not have any advantage over the use of a rate control strategy in patients with atrial fibrillation. However, the patients in that trial were elderly (mean age, 70 years) and didn't have that many symptoms, and the rhythm control strategy consisted of anti-arrhythmic drugs that had not been effective and had the potential for serious adverse effects.

So other methods of conversion to and maintenance of sinus rhythm was tried. One of them is circumferential pulmonary vein ablation. It has been proved effective in patients with paroxysmal or permanent chronic atrial fibrillation. ${ }^{26-31}$

Circumferential pulmonary vein ablation may exert its beneficial effects by eliminating "driver tachycardias" or "rotors" that could play a role in the genesis of atrial fibrillation, autonomic denervation of the left atrium, isolation of the pulmonary veins, atrial debulking and elimination of the arrhythmogenic foci outside the pulmonary veins..$^{32-37}$

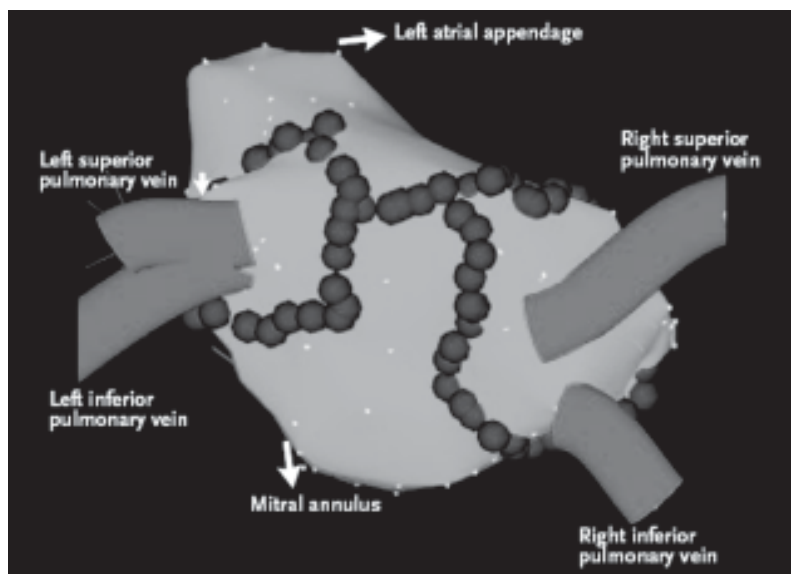

Fig.-1: Circumferential Pulmonary Vein Ablation ${ }^{38}$ 
Circumferential pulmonary vein ablation can be done by radiofrequency ablation, cryoablation and surgery. It can restore and maintain sinus rhythm in approximately $75 \%$ of patients with symptomatic, chronic atrial fibrillation, with a concomitant decrease in both the severity of symptoms and the diameter of the left atrium. ${ }^{38}$

\section{Exclusion of left atrial appendage}

A substantial number of patients with $\mathrm{AF}$ who are at high risk for thromboembolic events are not candidates for long-term warfarin. The left atrial appendix (LAA) is the place of thrombosis in patients with Atrial Fibrillation in $75 \%$ cases, and it can easily be excluded from the systemic circulation at the time of cardiac surgery by excision, ligation, suturing, or stapling. Currently, removal of the LAA at the time of mitral valve surgery is recommended to reduce future stroke risk. The ongoing LAA Occlusion Study (LAAOS) is evaluating the efficacy of the routine LAA occlusion in patients undergoing elective coronary artery bypass graft surgery. ${ }^{39}$

Recently, two devices specifically designed for percutaneous transcatheter LAA occlusion have been introduced: the Percutaneous LAA Transcatheter Occlusion(PLAATO; Appriva Medical Inc) and WATCHMAN LAA system (Atritech, Inc)

The WATCHMAN left atrial appendage system for embolic protection in patients with atrial fibrillation (PROTECT AF) study was designed to demonstrate the safety and efficacy of the WATCHMAN device in patients with nonvalvular AF who are eligible for long-term OAC.

The WATCHMAN left atrial appendage system is a 3-part system consisting of a trans- septal access sheath, a delivery catheter and an implantable nitinol device. The system is designed to facilitate device placement via femoral venous access via the transseptal route into the LAA. The WATCHMAN implant comprises a self expanding nitinol frame

structure with fixation barbs and a permeable polyester fabric that covers the atrial facing surface of the device. The device is constrained within a delivery catheter until deployment into the LAA. The WATCHMAN implant is available in diameters of 21, 27, 30 and 33 $\mathrm{mm}$. Device size is chosen to be $10 \%$ to $20 \%$ larger than the diameter of the LAA body.

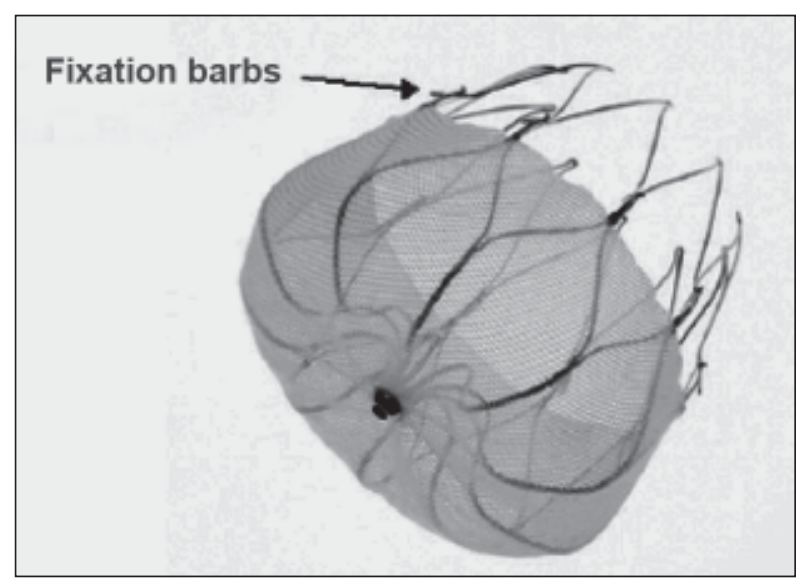

Fig.-2: WATCHMAN implant ${ }^{40}$

In PROTECT -AF study the procedure is done under TEE. Heparin is given during the procedure. After implantation patients are given aspirin 81 to $100 \mathrm{mg} /$ day and warfarin for at least 45 days, with dosage of the latter to keep the INR between 2 and 3.Successful placement of the device is defined if the LAA is completely sealed with absence of flow or minimal flow (jet $<3 \mathrm{~mm}$ ) as measured by TEE at 45 days.

This study demonstrated that implantation of the WATCHMAN device is generally safe and feasible. The annual risk of stroke based on the CHADS2 score in this study was calculated to be1ow 9/ year. In contrast, no strokes have occurred in any of the patients in this trial despite discontinuation of anticoagulation in $>90 \%$ cases and an average follow up of 2 years. ${ }^{40}$

Another device is being tried for LAA occlusionPLAATO system (ev3 Inc., Plymouth, Minnesota). In two prospective, multi-center trials, LAA occlusion was attempted in 111 patients (age 71 +/9 years). All patients had a contraindication for anticoagulation therapy and at least one additional risk factor for stroke. Implantation was successful in 108 of 111 patients. Average follow-up was 9.8 months. Two patients experienced stroke. No migration or mobile thrombus was noted on transesophageal echocardiogram at one and six months after device implantation. They concluded that closing the LAA using the PLAATO system is feasible and can be performed at acceptable risk. It may become an alternative in patients with $\mathrm{AF}$ and a contraindication for lifelong anticoagulation treatment. ${ }^{42}$ 

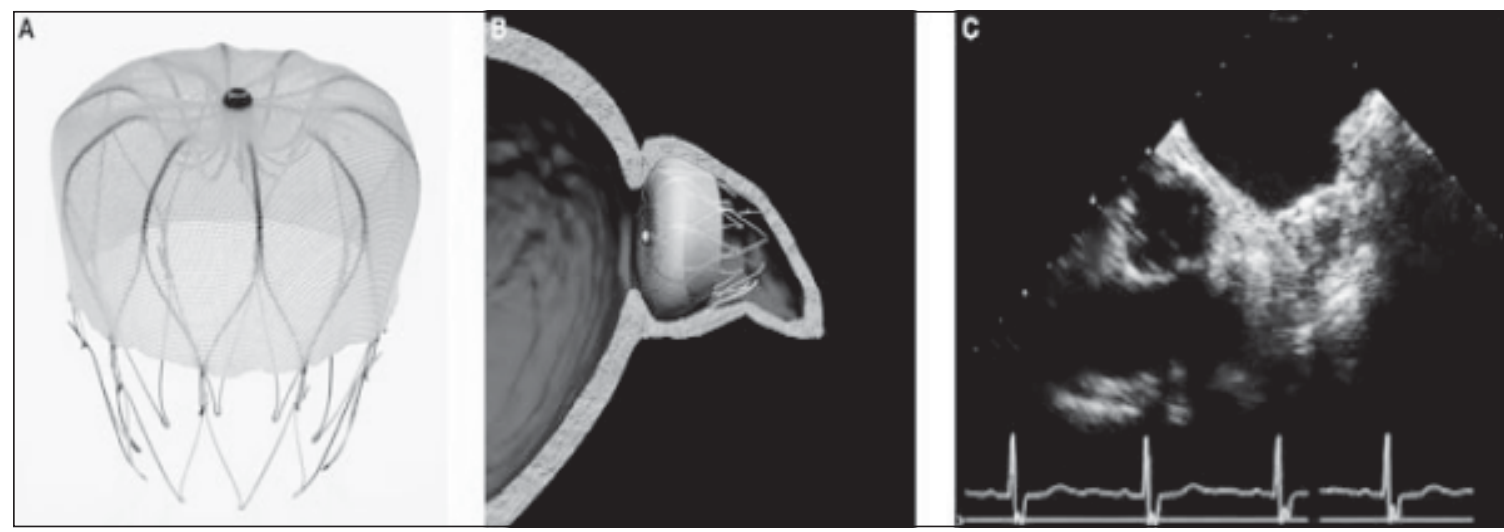

Fig.-3: The WATCHMAN ${ }^{\circledR}$ device (Atritech, Inc., North Plymouth, MN) ${ }^{41}$

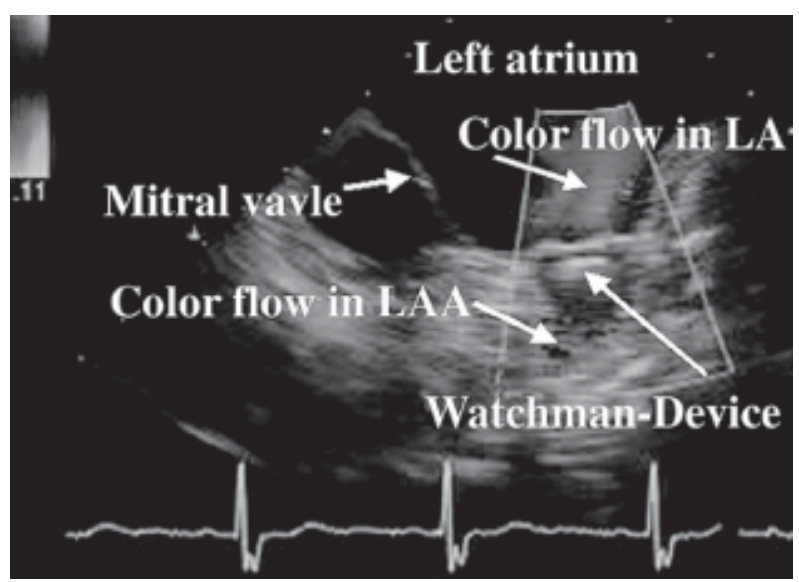

Fig.-4: - Well positioned WATCHMWN device in $L A A^{40}$.

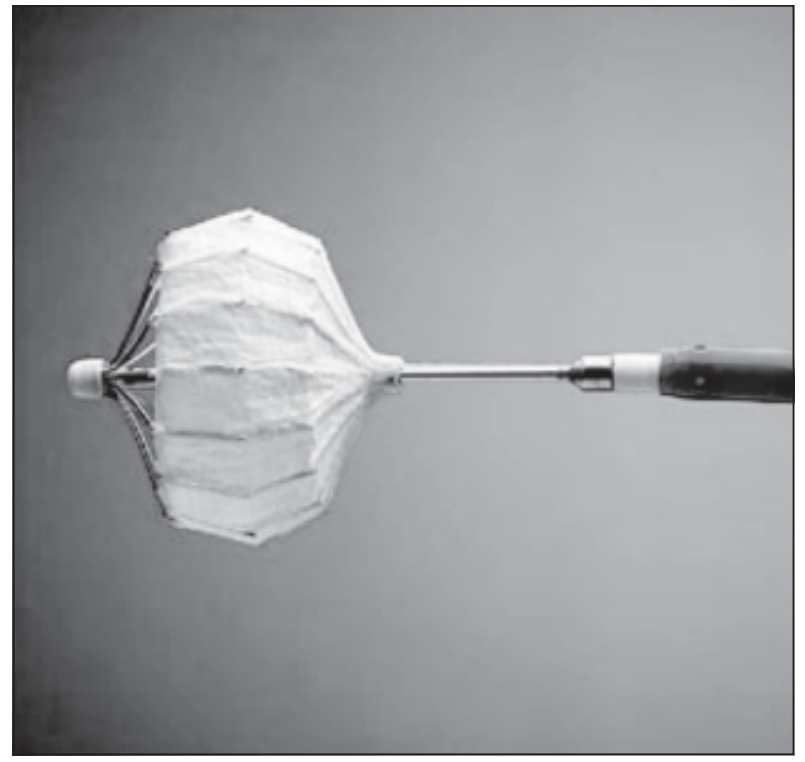

Fig.-5: PLAATO device system ${ }^{41}$
In another study 11 patients were enrolled to evaluate safety and feasibility of PLAATO system. All patients had contraindications to anticoagulation and had at least one risk factor for stroke. The predicted stroke risk for this cohort was $8.6 \%$ per year as calculated using the CHADS2 score. There was one stroke during follow up; the stroke risk was $3 \%$ per year. The observed stroke risk with PLAATO system was comparable to what would have been observed with warfarin. They concluded that the PLAATO device decreases the risk of stroke in a high risk cohort of AF patients. ${ }^{43}$

Up to December 2007 more than 200 PLAATO devices were implanted worldwide in patients with nonrheumatic AF who were at high risk for ischaemic stroke and not candidates for long-term oral anticoagulant. In a follow-up time of 258 patientyears, an estimated $61 \%$ reduction in stroke risk was achieved with PLAATO procedure. ${ }^{39}$

One of the major concerns of this device implantation is obstruction of LUPV and reduced LA function. It was evaluated in a study with 11 patients with atrial fibrillation. PLAATO device was used for LAA closure. It was concluded that PLAATO device achieved an adequate seal of the neck of the left atrial appendage without significant effect on the structure or function of the LA and LUPV. ${ }^{44}$

\section{Conclusion:}

Along with improvement in the treatment of IHD and heart failure; and increase in the number of cardiac surgery for IHD, congenital heart disease and valvular heart disease; and increase in life expectancy, the prevalence of Atrial fibrillation is also increasing. Warfarin is a proven drug for prevention of stroke in patients with atrial 
fibrillation. Newer anticoagulants are being tried, but not yet well established by clinical trials. Separation of left atrial appendage from circulation by surgery or device implantation is a promising one in this field. These new therapies will be able to avoid different limitations \& complications of warfarin therapy. These newer approaches are still recommended only in the patients who are at high risk of bleeding with warfarin therapy.

Conflict of Interest - None.

\section{References:}

1. Wolf PA, Abbott RD, Kannel WB. Atrial fibrillation as an independent risk factor for stroke: the Framingham Study. Stroke.1994; 37: 983-988.

2. Chugg SS, Blackshear JL,Shen WK et al. Epidemiology and natural history of atrial fibrillation: clinical implications. J Am Col Cardiol. 2001; 37: 371-378.

3. Risk factors for stroke and efficacy of atithrombotic therapy in atrial fibrillation: analysis of pooled data from five randomized controlled trials. Arch Intern Med.1994; 154: $1449-1457$.

4. Wolf PA, Abbott RD, Kannel WB. Atrial fibrillation: a major contributor to stroke in the elderly. Arch Intern Med. 1987; 147: 1561-1564.

5. Silverman M. From revellious palpitations to the discovery of auricular fibrillation: contributions of Mackenzie, Lewis and Einthoven. Am J Cardiol.1994; 73: 384-389.

6. Feinberg WM, Blackshear JL, Laupacis A et al. Prevalence, age distribution and gender of patients with atrial fibrillation: analysis and implications. Arch Intern Med.1995; 155: 432-435.

7. Bernard J Gersh, Teresa SM Tsang, Marion E Barnes, James B Seward. The changing epidemiology of nonvalvular atrial fibrillation: the role of novel risk factors.Eur H Journal. (Suppl 7). 2005; C5-C10.

8. Braunwald e. Shattuck lecture- cardiovascular medicine in the turn of the millennium: triumphs, concerns and opportunities. N Eng J of Med.1996; 337: 1360-1369.

9. Page RL, Wilkinson We, Clair WK et al. Asymptomatic arrhythmias in patients with symptomatic atrial fibrillation and paroxysmal SVT. Circulation. 1994.89: 224-227.

10. Rockson SG, Albers GW. Comparing the guidelines: anticoagulation therapy to optimize stroke prevention in patients with atrial fibrillation. J Am Col Cardiol. 2004; 43: 929-935.

11. Wolf PA, Abbott RD, Kannel WB. Atrial fibrillation as an independent risk factor for stroke: the Framingham study. Stroke.1991; 22: 983-988.

12. Ezekowitz MD, Levine JA. Preventing stroke in patients with atrial fibrillation. JAMA.1999; 281: 1830-1835.

13. Vaziri SM, Larson MG, Benjamin EJ, Levy D. Echocardiographic predictors of nonrheumatic atrial fibrillation. The Framingham Heart Study. Circulation. 1994; 89: 724-730.
14. Gaze BF, Waterman $\mathrm{AD}<\mathrm{Shanon} \mathrm{W}$ et al. Validation of clinical classification schemes for predicting stroke: results from the national registry of atrial fibrillation. JAMA. 2001; 285; 2864-2870.

15. Joseph E, Jean YLH, Philip MW Bath, Stuart JC. Indication for antithrombotic therapy for atrial fibrillation : reconciling the guidelines with clinical practice. Eur H Journal (Supp. 7). 2005; C28- C33.

16. McNamara RL, Tamariz LJ, Segal JB et al. Management of atrial fibrillation : review of the evidence for the role of pharmacological therapy, electrical cardioversion, and echocardiography. Ann Intern Med. 2002; 139: 10181033.

17. Wyse DG, Waldo AL, Dimarco JP et al. A comparison of rate control and rhythm control in patients with atrial fibrillation. N Eng J Med. 2002; 347; 1825-1833.

18. Van Gelder IC, Hagens VE, DiMarco JP et al. a comparison of rate control and rhythm control in patients with recurrent persistent AF. N Eng J Med. 2002; 347: 1834- 1840.

19. Hart RG, Benavente'O, Mcbride R et al. antithrombotic therapy to prevent stroke in patients with atrial fibrillation : a meta analysis. Ann Intern Med. 1994; 131: 1449-1457.

20. Risk factors of stroke and efficacy of antithrombotic therapy in atrial fibrillation. Analysis of pooled data from randomized control trials. Arch Intern Med. 1994; 154: 1449-1457.

21. EAFT (European Atrial Fibrillation Trial) Study group. Secondary prevention in non- rheumatic atrial fibrillation after TIA or minor stroke. Lancet. 1993; 342: 1255-1262.

22. Stroke Prevention in atrial fibrillation Investigators. Warfarin versus aspirin for prevention of thromembolism in atrial fibrillation: stroke prevention in at6rial fibrillation: stroke prevention in atrial fibrillation II study. Lancet. 1994; 343: 687-691.

23. Segal JB, McNamara RL, Miller MR et al. Prevention of thromembolism in atrial fibrillation. A meta analysis of trials of anticoagulants and antiplatelet drugs. J Intern med . 2000; 15: 56-67.

24. Sam Schulman, Rebecca J. beyth. Risk of bleeding with long term anti-thrombotic therapy in atrial fibrillation. European Heart Journal supplements (2005); 7 (supplement C), C34-C40.

25. SPORTIF Executive steering committee for the SPORTIF V investigators. Ximelagatran vs Warfarin for stroke prevention in patients with nonvalvular atrial fibrillation: A randomized trial. JAMA. 2005; 293(6): 690-698.

26. The AMADEUS Investigators. Comparison of Indraparinux with vitamin $\mathrm{K}$ antagonists for prevention of thromboembolism in patients with atrial fibrillation: a randomized, open label, non-inferiority trial. Lancet.2008; 371: 315-22. 
27. Kottkamp H, Tanner H, Kobza R et al. Time courses and quantitative analysis of atrial fibrillation episode number and duration after circular plus linear left atrial lesions: trigger elimination or substrate modification: early or delayed cure? J Am Coll Cardiol. 2004; 44: 869-77.

28. Oral H, Scharf C, Chugh A et al. Catheter ablation for paroxysmal atrial fibrillation: segmental pulmonary vein ostial ablation vs. left atrial ablation. Circulation.2003; 108: 2355-60.

29. Pappone C, Manguso F, Vicedomini G et al. Prevention of iatrogenic atrial tachycardia after ablation of atrial fibrillation: a prospective randomized study comparing circumferential pulmonary vein ablation with a modified approach. Circulation. 2004; 110: 3036-42.

30. Pappone C, Oreto G, Rosanio S et al. Atrial electroanatomic remodeling after circumferential radiofrequency pulmonary vein ablation: efficacy of an anatomic approach in a large cohort of patients with atrial fibrillation. Circulation. 2001; 104: 2539-44.

31. Pappone C, Rosanio S, Augello G et al. Mortality, morbidity and quality of life after circumferential pulmonary vein ablation for atrial fibrillation: outcome from a controlled nonrandomized long-term study. $J$ Am Coll Cardiol. 2003; 42: 185-97.

32. Jalife J. Rotors and spiral waves in atrial fibrillation. $J$ Cardiovasc Electrophysiol. 2003; 14: 776-80.

33. Nadamanee K, McKenzie J, Kosar E et al. A new approach for catheter ablation of atrial fibrillation: mapping of the electrophysiologic substrate. $\mathrm{J} \mathrm{Am} \mathrm{Col}$ Cardiol. 2004; 43: 2044-53.

34. Pappone C, Santinelli V, Manguso F et al. Pulmonary vein denervation enhances long term benefit after circumferential ablation for paroxysmal atrial fibrillation. Circulation. 2004; 109: 327-34.

35. Stabile G, Turco P, La Rocca V, Nocerino P, Stabile E, De Simone A. Is pulmonary vein isolation necessary for curing atrial fibrillation? Circulation. 2003; 108: 657-60.
36. Moe GK. A conceptual model of atrial fibrillation. $J$ Electrocardiol. 1968; 1: 145-46.

37. Lin WS, Tai CT, Hsieh MH et al. Catheter ablation of paroxysmal atrial fibrillation initiated by non-pulmonary vein ectopy. Circulation. 2003; 107: 3176-83.

38. Hakan Oral, Carlo Pappone, Aman Chugh, Eric Good et al. Circumferential pulmonary vein ablation for chronic atrial fibrillation. N Eng J Med.2006; 354: 934941.

39. Orhan Onalan, Eugene Crystal. Left Atrial Appendage Exclusion for Stroke Prevention in Patients With Nonrheumatic Atrial Fibrillation. Stroke. 2007; 38: 624.

40. Peter B. Sick, Gerhard Schuler, Karl Eugen Hauptmann, Eberhard Grube, Steve Yakubov, Zoltan G. Turi, Gregory Mishkel, Steve Almany, MD, David R. Holmes. Initial worldwide experience with the watchman left atrial appendage system for stroke prevention in atrial fibrillation. J Am Coll Cardiol. 2007; 49: 40.1490-95.

41. Syed TM and Halperin JL. Left atrial appendage closure for stroke prevention in atrial fibrillation: state of the art and current challenges. Nat Clin Pract Cardiovasc Med .2007; 4: 428-435

42. Ostermayer HS, Reisman M, Kramer PH, Matthews RV, Gray WA, Block PC. Percutaneous left atrial appendage transcatheter occlusion (PLAATO system) to prevent stroke in high- risk patients with nonrheumatic atrial fibrillation: results from the international multicenter feasibility trials. J Am Coll Cardiol. 2006; 47(7): 1500-1.

43. Mikhael F. El-Chami,Parker Grow, Dana Elien, Stamatios Lerakis, Peter C. Block. Clnical outcomes three years after PLAATO implantation. Catheterization and Cardiovascular Interventions. 2007; 69: 704-707.

44. Ibrahim R. Hanna, Paul Kolm, Randolph Martin,Mark Reisman, William Gray, Peter C. Block. Left atrial structure and function after percutaneous left atrial appendage transcatheter Occlusion (PLAATO) - six months echocardiographic follow up. J Am Coll Cardiol.2004; 43: 1868-72. 